Rafaela Sayas Contreras** Katleen Marún Uparela***

\title{
Sanción a los negocios jurídicos en Colombia: restitución vs indemnización*
}

\author{
Sanction to the juridical business in Colombia: \\ restitution vs indemnification
}

Recibido: 25 de septiembre de 2013 / Aceptado: 30 de octubre de 2013

\begin{abstract}
Palabras clave:
Nulidad, Restitución, Perjuicios, Indemnización, Causales de nulidad.
\end{abstract}

Key words: Nullity, Restitution, Injuries, Indemnification, Causes of Nullity.

\begin{abstract}
Resumen
El presente artículo de reflexión analiza el actual contexto del Derecho Privado colombiano, en razón a la evolución de las negociaciones, donde se evidencian situaciones que escapan a lo normativo, como consecuencia de la antigüedad del Código Civil. Una de ellas, está en el Art. 1746 del Código en mención, que regula los efectos de la nulidad como sanción a los negocios jurídicos. En él, se plantea como consecuencia principal de la nulidad, la retrotracción del contrato, mediante un régimen de restituciones mutuas; además dispone lo relacionado con las mejoras y abonos hechos a la cosa objeto del negocio jurídico, pero no establece una directriz para el caso de la reparación de perjuicios derivados de la declaratoria de nulidad del negocio jurídico, al contratante que haya actuado de buena fe. Es precisamente por esta razón que el propósito de esta investigación es determinar si el texto del Art. 1746 del Código Civil es una herramienta eficaz para los contratantes que sufran algún tipo de perjuicio derivado de la nulidad o si por el contrario esto supone la necesidad de iniciar un nuevo proceso para reclamar esos perjuicios y elaborar una nueva propuesta normativa del artículo acorde con el contexto.
\end{abstract}

\begin{abstract}
The present article of reflection analyzes the current context of the private Colombian right, in reason to the evolution of the negotiations, where there are demonstrated situations that escape to the normative thing, as consequence of the antiquity of the Civil Code. One of them, it is in the Art. 1746 of the Code in mention, which regulates the effects of the nullity as sanction to the juridical business. In, it appears as principal consequence of the nullity, the retrotracción of the contract, by means of a regime of mutual restitutions, in addition he arranges the related thing to the improvements and credits done to the thing. I object of the juridical business, but it does not establish a directive for the case of the repair of prejudices derived from the declaration of nullity of the juridical business, to the contractor who has acted of good. It is precisely for this reason that the intention of this investigation is to determine if the text of the art. 1746 of the Civil Code is an effective tool for the contractors who suffer some type of prejudice derived from the nullity or if on the contrary this supposes the need to initiate a new process to claim these prejudices and to elaborate a new normative offer of the article according to the context.
\end{abstract}

\footnotetext{
* El presente artículo de reflexión corresponde a un Informe de avance de proyecto de investigación "Nuevas dinámicas del Derecho Privado" que está siendo ejecutado por el Grupo de Investigación Conflicto y Sociedad de la Universidad de Cartagena.

** Abogada, máster en Derecho de la Universidad Nacional de Colombia, Ph.D. en Sociología de la Universidad de Belgrano (Argentina), candidata a Ph.D. en Ciencias Sociales UBA (Argentina), docente Investigadora de la Facultad de Derecho y Ciencias Políticas de la Universidad de Cartagena. Directora del Grupo de Investigación Conflicto y Sociedad. rafaelaester@gmail.com

*** Estudiante de Derecho y Ciencias Políticas de la Universidad de Cartagena, integrante del semillero Réplica Jurídica, adscrito al Grupo de Investigación Conflicto y Sociedad, dirigido por la doctora Rafaela Sayas Contreras, reconocido por Colciencias. katleenmu@gmail.com
} 


\section{INTRODUCCIÓN}

Debido al carácter tradicionalista de nuestro Derecho Civil y la ardua conservación de algunas instituciones y figuras del Derecho romano, como el riguroso y estricto formalismo que caracteriza la actividad jurídica, se ha hecho necesario que para poder hablar del grado de validez de un negocio jurídico tengamos que recurrir inmediatamente a hacer un minucioso examen del cumplimiento de ciertas formalidades exigidas. De acuerdo con Zannoni (2004), "El ius civile muestra un formalismo riguroso que conlleva a que la validez de los negocios jurídicos resida en el cumplimiento de las formas".

Es precisamente en el contexto de este examen valorativo de formalidades, que cualquier anomalía o disparidad con lo exigido por la ley se convierte en la razón principal para que el negocio jurídico sea merecedor de una sanción. En este sentido, la sanción se constituye en la forma de desaparecer de la vida jurídica una relación que desde el momento de su celebración ha sido defectuosa, restándole sus efectos jurídicos, para evitar precisamente que por su falta de concordancia con el ideal de negocio jurídico que la ley ha prescrito, se generen conflictos entre los contratantes. En concordancia con lo anterior Ghersi (2005) plantea que:

"El ordenamiento jurídico reacciona mediante la sanción para evitar una situación jurídica que se considera disvaliosa. Tratando en la nulidad del contrato de retrotraer la regulación al momento inmediatamente anterior a la celebración como si dicha relación jurídica nunca hubiera existido".
En este sentido, la nulidad como sanción al negocio jurídico consiste en que mediando autoridad judicial, se logre dejar sin efectos jurídicos un determinado negocio ya celebrado, y retrotraer las situaciones al estado jurídico anterior a su celebración, a causa de la materialización de situaciones como el objeto ilícito o la causa ilícita en el negocio, la incapacidad de las partes, un vicio en el consentimiento o el desconocimiento de una norma de orden público.

La nulidad como sanción puede ser de dos clases dependiendo del tipo de irregularidad que presente el negocio jurídico, así pues tenemos que la nulidad absoluta puede ser declarada judicialmente cuando el negocio se contrapone a una norma de orden público o carece de alguno de sus elementos constitutivos esenciales que son a saber un objeto lícito, causa lícita o la capacidad absoluta de las partes para contratar. En tanto que si el negocio presenta una inconsistencia por fuera de estas situaciones contempladas como causales de nulidad absoluta, estaremos entonces en el terreno de la nulidad relativa, de conformidad con los artículos 1740 y 1741 del Código Civil colombiano.

Es pertinente en este punto mencionar, que a pesar de que el Código fue claro en definir qué situaciones daban lugar a la nulidad absoluta, no lo fue al respecto de la nulidad relativa, ya que solo el artículo 1740 advirtió que cualquiera otra especie de vicio produce este tipo de nulidad, por ello no puede pensarse que la nulidad relativa es una categoría cerrada, sino que en ella pueden encajar varios supuestos que doten de irregularidad al negocio jurídico, y fue dentro 
de la lógica actual una buena decisión, ya que al no establecer una categoría cerrada y taxativa de causales para esta nulidad, se da cabida a que situaciones y fenómenos, que al momento de la confección de la norma no existían, y que hoy o en el futuro, llegaren a existir, puedan encajar como nulidad, a diferencia de lo que sucede con las normas taxativas, que dejan por fuera algunas situaciones.

En atención a la antigüedad de las normas que rigen nuestro Derecho Civil, y debido a que fueron pensadas para una realidad jurídica muy diferente a la actual, muchas de ellas hoy resultan anacrónicas, debido a su redacción, estas no se ajustan en gran medida a las exigencias de las nuevas tendencias en Derecho Privado, ni a las necesidades de los contratantes. En atención a la función social del Derecho de evitar controversias, este debe evolucionar, cambiar formas, normas y estructuras para ser un instrumento de descongestión y solución de conflictos y esto solo puede lograrse a través de la reestructuración de ciertas normas como las de nuestro actual Código Civil, que como se ha dicho, no responden a las demandas del Derecho Privado del siglo XXI, por ello es, estos aspectos deben ser investigados. Con la intención de contribuir a la evolución normativa del Derecho Privado colombiano, se abordará el estudio de una situación particular del artículo 1746 del Código Civil colombiano, que regula lo relacionado con los efectos de la declaratoria de la nulidad y que por su contenido actual genera conflictos en el plano fáctico, para luego proponer una nueva re- dacción de la norma acorde con las necesidades del contexto.

En esta línea se propuso el proyecto de investigación "Nuevas dinámicas del Derecho Privado" llevado a cabo por el Grupo de Investigación Conflicto y Sociedad de la Universidad de Cartagena, proyecto de cuyo desarrollo, presentamos el primer informe de avance.

\section{METODOLOGÍA}

Se trata de una investigación eminentemente jurídica, de tipo analítico, documental, de carácter cualitativo, que se desarrollará a nivel dogmático teórico; la cual busca recopilar, sistematizar y analizar el sistema de nulidades vigente en Colombia, para pasar luego a la descripción y análisis de un caso en el que se evidencie las falencias del sistema que serán descritas. La parte propositiva, consistirá en estructurar una propuesta de la nueva redacción de la norma que establece los efectos de la nulidad, para subsanar las irregularidades que en la actualidad presenta la figura. Las técnicas de recolección de la información, es la del análisis documental sobre información de carácter secundario.

Metodológicamente hablando el cuerpo del trabajo se organizará en las siguientes partes: primero será desarrollada una breve introducción acerca del tema, en segundo lugar, se tratará de la reglamentación que se le ha dado en el ordenamiento jurídico colombiano a las nulidades como sanción al negocio jurídico, en tercer lugar se estudiarán las nulidades y su tratamiento en algunas doctrinas extranjeras, luego de esto será presentado el estudio de un caso con 
el que se pretende demostrar la tesis planteada y finalmente serán expuestas algunas posibles soluciones y las conclusiones producto de la investigación.

La ponencia girará en torno a la siguiente pregunta problema: ¿Guarda coherencia el sistema actual de nulidades regulado por el Código Civil colombiano con derecho de los contratos y las necesidades de los contratantes?

\section{Las nulidades y sus efectos en el Derecho Privado colombiano}

La nulidad como sanción al negocio jurídico, como ya se mencionó anteriormente, según las causales que dan origen a esta, puede clasificarse en absoluta y relativa, pero realmente para los efectos de nuestra investigación eso es irrelevante, puesto que independientemente de las causales, los efectos siguen siendo los mismos, tiene fuerza de cosa juzgada y da a las partes el derecho a ser restituidas al mismo estado en el que se encontrarían de no haberse celebrado el contrato nulo.

El Código Civil colombiano regula las nulidades en los artículos del 1740 al 1756, que en síntesis las definen, clasificándolas en absolutas y relativas, establecen aspectos relativos a su declaratoria, a su ratificación y además señala los efectos al ser declarada, en el artículo 1746 diciendo que:

"La nulidad pronunciada en sentencia que tiene la fuerza de cosa juzgada, da a las partes derecho para ser restituidas al mismo estado en que se hallarian si no hubiese existido el acto o contrato nulo; sin perjuicio de lo prevenido sobre el objeto o causa ilícita. (Las subrayas son nuestras).

En las restituciones mutuas que hayan de hacerse los contratantes en virtud de este pronunciamiento, será cada cual responsable de la pérdida de las especies o de su deterioro, de los intereses y frutos, y del abono de las mejoras necesarias, útiles o voluptuarias, tomándose en consideración los casos fortuitos, y la posesión de buena fe o mala fe de las partes; todo ello según las reglas generales y sin perjuicio de lo dispuesto en el siguiente artículo".

Este artículo al consagrar los efectos de la declaración de nulidad, establece que las partes en virtud de una sentencia que declara la nulidad de un determinado negocio jurídico, tienen derecho a ser restituidas al mismo estado en el que se hallarían si no se hubiese llevado a cabo el acto o contrato nulo, con ello se persigue uno de los principales efectos de esta figura, que es precisamente desencadenar la restitución, es decir, el llevar a los contratantes a una situación tal en la que se retrotraigan las consecuencias de la celebración del contrato que fue objeto de la declaración de nulidad. Es aquí donde cabe hacernos algunos cuestionamientos con relación a esta figura: ¿permite la estructura de la norma jurídica comentada, el artículo 1746 Código Civil, deducir que las partes llegarán a ese estado de indemnidad mediante el establecimiento de un régimen de restituciones mutuas? ¿Es el texto del artículo 1746 una herramienta eficaz para los contratantes que sufran algún tipo de perjuicio derivado de la nulidad? ¿Supone esto la necesi- 
dad de iniciar un nuevo proceso para reclamar esos perjuicios? ¿En el Derecho Privado colombiano existe la posibilidad, de que paralelamente se tramite una nulidad y un proceso de indemnización perjuicios sufridos a causa de la sanción al negocio jurídico?

Comoquiera que el Derecho debe propender por solucionar conflictos y por la reparación integral a los perjudicados, es importante en el Derecho colombiano, encontrar respuestas a preguntas como estas, que en esencia cuestionan la real efectividad y operatividad de ciertas normas jurídicas. En ocasiones lo que se logra dilucidar al resolver ese tipo de cuestionamientos, puede llevarnos a la conclusión de que en realidad son más las normas de Derecho sustantivo y su falta de claridad en redacción, las que están entorpeciendo la actividad judicial colombiana, congestionándola con procesos innecesarios, que no tienen que ver con problemas de índole procesal. En este sentido señala Poveda (2010):

"Las diferentes reformas que se han producido al sistema judicial colombiano -administrativas y procesales-, se han ejecutado sin que se cuente para ello con un diagnóstico que determine los efectos positivos de los cambios, $y$, muchas veces, en el trámite de un proyecto de ley aparecen normas que luego como ley vigente resultan contradictorias, confusas o llenas de lagunas, produciendo mayores problemas en el momento de su aplicación".

Las reformas en el Derecho adjetivo pueden llegar a cumplir esa función de descongestión judicial y hacer que el ritmo de la actividad judicial sea más acorde con esa noción de justicia oportuna y adecuada, pero no es posible desconocer, que el Derecho sustantivo no puede seguir siendo en algunos casos la causa de la congestión judicial. El Derecho sustancial debe ser más claro, preciso, debe procurar en lo menos posible que aspectos gramaticales, terminen significando un nuevo proceso que atender por un juez colombiano, así las cosas el propósito es que el Derecho sustantivo deje de ser algunas veces el origen de un nuevo conflicto, ya que es algo en lo que se debe estar enfocado, en esta época de cambios normativos en materia procesal, porque no solo se trata de hacer que los procesos para resolver los conflictos sean más rápidos, sino también de evitar los conflictos mismos. Siguiendo esta misma línea de pensamiento, Namen (2010) afirma que: "El exceso y la dispersión normativa son irrefutables. Esto atenta contra la plenitud sistémica del ordenamiento jurídico, la seguridad y certeza y, por tanto, contra los derechos, libertades y garantías. Las codificaciones deben revisarse y adaptarse a la era actual".

Como es sabido, un acto jurídico, no pierde validez ni eficacia hasta tanto su nulidad no sea declarada mediante sentencia judicial, una vez esta se produce, el acto deja de tener efectos hacia el pasado y hacia el futuro, se reconoce entonces el efecto retroactivo de la nulidad, es por ello que lo que se busca, es que las partes vuelvan al estado anterior a la celebración del contrato, suprimiendo sus efectos jurídicos. Así pues, por traer un ejemplo a colación, una vez celebrado un contrato de compraventa, que es 
declarado nulo posteriormente, las partes en virtud de la declaratoria de nulidad deben respectivamente devolver la cosa y restituir el precio, tal como lo indica el régimen de prestaciones mutuas del códice, que especifica todo en cuanto a los frutos, modificaciones y alteraciones que haya sufrido la cosa.

Pero es en este punto precisamente donde está la falla del artículo 1746 que analizamos, porque solo por medio de unas restituciones mutuas como producto de la nulidad es muy difícil que las partes puedan resarcir los daños que se causen a raíz de la declaración de nulidad del acto, no siempre al devolver la cosa y restituir el precio se hace justicia, de hecho, puede darse el caso, que queden por fuera una serie de perjuicios que puedan generarse por el cese de los efectos del contrato celebrado, ¿cómo se logra entonces la reparación integral de los per juicios?

Teniendo en cuenta las necesidades actuales de los contratantes y el ritmo de las negociaciones del siglo XX, no podemos seguir pensando que la declaratoria de un determinado negocio jurídico como nulo, solo va a producir efectos única y exclusivamente sobre este, en el entendido de que la sentencia sí va a producir efectos jurídicos solo sobre ese negocio jurídico en concreto, pero los efectos económicos y negociales pueden trascender a este negocio y afectar a otros que dependían de la efectiva ejecución de este, ocasionando perjuicios mayores a la parte contratante afectada; ya que esta, no solo perderá el negocio que fue declarado nulo, sino también todos los que de este dependían, quedando sin más alternativa, según lo señalado por el artículo 1746, en el marco de un régimen de restituciones mutuas, sin contemplar la norma la posibilidad alguna de ser resarcido por perjuicios colaterales que se produzcan a raíz de la buena fe que se depositó en la celebración del contrato, por parte del contratante que no dio lugar a la sanción del negocio.

Podría pensarse de la lectura del Título XX del Código Civil, que esa información es todo lo que el Código regula en materia de los efectos de la nulidad como sanción al negocio jurídico, pero en efecto no es así, puesto que si bien de manera clara en el artículo 1746, se señalan los efectos de su declaratoria, existen a lo largo del articulado del Código Civil algunas disposiciones que modifican esos aspectos, ya que regulan situaciones en las que se contempla la posibilidad de una indemnización cuando se está en presencia de un vicio del consentimiento, lo cual representa para los contratantes perjudicados una oportunidad de ser resarcidos, aunque queda por determinar el alcance de estas indemnizaciones, qué tipologías del perjuicio cubren y si llega a indemnizarse la pérdida de la oportunidad negocial, que es lo que actualmente más afecta a los contratantes.

Como habíamos mencionado anteriormente, el Código contempla unas cuantas disposiciones aisladas que nos permiten tener un atisbo de lo que llamaríamos una indemnización ligada a una declaración de nulidad, pero nos servimos aclarar, que esto no se da con respecto a todas 
las causales de la sanción del negocio jurídico, ni es una indemnización en términos de reparación integral.

Para demostrar lo afirmado, nos referiremos a los artículos que tocan el tema, en primer lugar tenemos el artículo 1512 que nos habla del error en la persona, en el que se establece que este tipo de error no vicia el consentimiento, a menos de que el error sea la causa principal por la que se haya contratado, y en tal caso la persona con la que erradamente se contrató tiene derecho a ser indemnizada en los perjuicios en que de buena fe haya incurrido por la declaración de nulidad del contrato. Entonces vemos aquí cómo se pagan los perjuicios causados de buena fe, en una causal de nulidad relativa como lo es el vicio en el consentimiento por error en la persona, es decir, encontramos una indemnización de perjuicios que se vincula con una declaración de nulidad de un negocio jurídico.

El segundo caso se presenta en el artículo 1515 cuando el consentimiento está viciado por dolo, en esta situación se da lugar a la oportunidad de hacer uso de la acción de perjuicios contra la persona que ha actuado con dolo o contra quienes se han aprovechado de él, debiendo la primera pagar el valor total de los perjuicios $\mathrm{y}$ las segundas hasta la concurrencia del provecho que han tenido.

Y como último caso tenemos el del artículo 1747, que es la restitución debida por la nulidad causada por contratar con incapaces, en cuyo caso no se puede exigir restitución ni reembolso, a menos que se demuestre que la persona incapaz ha reportado algún provecho económico con el contrato celebrado, y en tal caso solo podrá pedir restitución o reembolso de lo que pagó o gastó, lo cual no se configura como una indemnización, sino como la restitución de un valor en dinero que fue previamente entregado, y que se convierte en una sanción al contratante negligente que no se informa de la capacidad del otro contratante.

Entonces de lo anterior se colige que solo tenemos tres causales y tres posibles indemnizaciones ligadas a la nulidad, pero ¿qué sucede entonces, si la nulidad ocurre por cualquier otra causal? Ya que si recordamos, las nulidades relativas no son taxativas y no existen en el Código todos los supuestos normativos que contemplen la indemnización posible para cada caso, como tampoco una indemnización genérica adjunta a la nulidad, para que se haga efectiva cuando se dé la causación de un perjuicio al declarar el negocio nulo. La redacción actual del artículo 1746 no nos permite pensar en una indemnización ligada a la nulidad en estos casos, o por el contrario nos obliga a iniciar un nuevo proceso judicial para conseguir la verdadera indemnidad.

\section{Tratamiento de las nulidades en doctrinas} extranjeras

Con relación al tema de indemnizaciones ligadas a acciones de nulidad o dentro de un proceso en el que se declare la nulidad, algunos autores foráneos han desarrollado algunos aspectos que tocan con lo aquí estudiado, es así como para el caso chileno Baraona (2006) plantea que: 
"A diferencia de las declaraciones de nulidad derivadas de un acto administrativo, en Chile han sido muy poco estudiadas las demandas de daños y perjuicios asociadas a una acción de nulidad de un acto o contrato. "Nuestro Código Civil chileno no contempla una regla general en la materia ni tampoco una particular que agrupe los casos de vicios en el consentimiento. Sin embargo, existen algunos artículos aislados que sí se refieren a la posibilidad de demandar daños y perjuicios como consecuencia de la celebración de un acto o contrato nulo".

El autor termina por afirmar que:

"[L]a indemnización de daños y perjuicios es compatible con la demanda de nulidad absoluta o relativa, como también lo puede ser con una demanda reconvencional de daños $y$ perjuicios de parte de quien debe sufrir la nulidad de un contrato. Pero la procedencia dependerá, naturalmente, de la causal invocada, de las circunstancias en que se ha celebrado el contrato y del estado en que se encuentren las partes respecto del vicio invocado. Los extremos mínimos que deben darse, aparte de los presupuestos generales de toda pretensión resarcitoria, son: 1) que quien pida la nulidad y quiera ser indemnizado, esté de buena fe respecto del vicio que la produce; 2) que contra quien se pida la indemnización pueda atribuírsele la inducción dolosa al contrato, o al daño, sea por dolo directo o al menos por una reticencia o negligencia respecto del vicio".

Por otro lado, tenemos los estudios que so- bre nulidad, restituciones y responsabilidad, ha hecho la autora francesa Catherine Thibierge (2008), quien asume una posición un tanto polémica al afirmar que cuando se habla de la máxima quod nullum est nullum producit efectum, se está haciendo referencia a los efectos de la nulidad en cuanto esta deja sin efectos jurídicos valga la redundancia, al acto nulo, haciendo énfasis en la diferencia que existe entre los efectos jurídicos y las consecuencias materiales de un acto de esta índole, y que cuando se habla de retrotraer el contrato, se está hablando entonces de restitución, y no de nulidad, porque es la restitución la institución jurídica que en palabras de la autora tiende a la vuelta de un patrimonio a su estado anterior, borrando las consecuencias de las prestaciones, por lo que afirma que, "es esta -la restitución-la que se ocupa de las consecuencias materiales del acto, mientras que la nulidad lo hace en el plano jurídico". Por ello Thibierge (2008) plantea que:

"La nulidad no suprime todas las consecuencias del acto, sino solo las consecuencias jurídicas (...) la supresión de esas consecuencias materiales producidas por la ejecución del acto anulado resulta de restituciones, distintas de la nulidad misma.

"Ahora bien: las acciones de nulidad y de restitución no tienden al mismo fin; si la acción de nulidad tiende a la supresión de los efectos jurídicos ilícitos del acto, es decir, de la situación de derecho que él creó, la acción de restitución tiende a la supresión de sus consecuencias materiales, es decir, a la situación de hecho consecutiva a su ejecución". 
Así las cosas, deja muy en claro esa distinción entre los efectos de la nulidad y la restitución, acierta en tocar un punto clave que tiene mucho que ver con el tema de los perjuicios derivados de la nulidad, al hablar de "la vuelta al estado anterior consiguiente a la reparación". En este punto señala que se daría esta reparación si el perjuicio se deriva de la celebración de un contrato, por la culpa precontractual de la otra parte, que origina la nulidad y sin la cual el acto no se habría llevado a cabo.

\section{Estudio de caso}

Para hacer más explícita la tesis que se ha venido desarrollando en esta investigación, analizaremos el caso que ilustra la sentencia de la Corte Suprema de Justicia, proferida el 16 de septiembre de 2011, con ponencia de Arturo Solarte Rodríguez.

En la sentencia en comento se analiza la controversia suscitada por la declaratoria de nulidad de un contrato de promesa de compraventa celebrado el 14 de noviembre de 1974, entre el señor Alfonso Pazos Mosquera y la empresa Pulpapel S.A., dedicada a la producción maderera, acordándose como precio del predio la suma de $\$ 210.000$, que serían cancelados así: $\$ 80.000$, que la prometiente compradora canceló en esa fecha, y \$130.000, para el día en que se otorgara la escritura pública, que perfeccionaría el contrato prometido, lo cual tendría lugar en la Notaría 1a. del Círculo de Popayán, 20 días después de que ocurriera la última de dos condiciones, haberse protocolizado y registrado la causa mortuoria de Herminia Pazos, en la cual se adjudi- cara la parte del inmueble de esta al prometiente vendedor $\mathrm{y}$, haberse registrado la sentencia por virtud de la cual el prometiente vendedor hubiere adquirido por prescripción extraordinaria el dominio de la parte del predio que tenía en calidad de poseedor.

Luego de haber sido entregado por Pulpapel S.A. una parte del precio, mediando autorización del señor Pazos, la empresa trasladó sus actividades comerciales y productivas al predio "La Cohetera", con el fin de iniciar la siembra de unos árboles de pino. Luego de haberse hecho la respectiva siembra de las coníferas en sucesivas ocasiones, seis años después de la firma del contrato de promesa de la compraventa, mediante sentencia del 28 de octubre de 1980, proferida por el Juzgado Segundo Promiscuo Municipal de Cajibío en el sucesorio de Herminia Pazos Mosquera, se adjudicaron a Alfonso Pazos los derechos que ostentaba sobre el inmueble la causante, quedando así la totalidad del predio en cabeza de este, quien falleció en 1984 sin haber concluido la negociación con la sociedad demandada.

Tramitada la causa mortuoria del señor Pazos, en la sentencia aprobatoria de la partición, se adjudicó en común y proindiviso el dominio del inmueble a sus hijos, los demandantes, quienes quedaron legitimados para invocar la nulidad de la promesa de compraventa, como en efecto ocurrió, con la sentencia del 22 de abril de 1994, ordenando a la demandada restituir a los demandantes el inmueble objeto de la promesa de compraventa y a estos el precio recibido por su padre, además condenó a aquellos 
a pagarle a Pulpapel S.A., quien había hecho las siembras y mejoras en el predio, para adecuarlo a su actividad, la suma de \$ 58'494.008, correspondientes a gastos ordinarios invertidos en la producción de los frutos civiles, así como \$ 59’212.875, por concepto de mejoras útiles realizadas en el predio.

Al momento de hacer la debida restitución del inmueble, la empresa Pulpapel procedió a talar las plantaciones de coníferas que había sembrado, actividad para la cual había decidido adquirir el predio, y que había sido consentida por el promitente vendedor, ya que ello representaba una gran inversión y el cumplimiento de su actividad comercial ordinaria.

Al recibir el inmueble los herederos de Alfonso Pazos, como producto de la restitución que ordenó la sentencia de nulidad, advirtieron que esta había sido entregada sin los árboles de pino, a pesar de que la sentencia ordenó la restitución por parte de la demandada a los demandantes, del predio "La Cohetera", junto con las cosas que formaran parte de él o que se reputaran como inmuebles por su conexidad. Con base en esto, los herederos del señor Pazos, inician el proceso objeto de la sentencia citada, para declarar que Pulpapel había incurrido en responsabilidad civil contractual y les había causado perjuicios, materializándose en la tala y aprovechamiento de las plantaciones madereras que la demandada extrajo de la finca "La Cohetera", ya que al estar estos sembrados, se convertían en parte integrante del predio y debían ser restituidos junto con él. En atención a lo dispuesto en el artículo 716 del Código Civil colombiano:
“Artículo 716. < Derechos sobre los frutos naturales $>$. Los frutos naturales de una cosa pertenecen al dueño de ella; sin perjuicio de los derechos constituidos por las leyes, o por un hecho del hombre, al poseedor de buena $f e$, al usufructuario, al arrendatario.

Así, los vegetales que la tierra produce espontáneamente o por el cultivo, y las frutas, semillas y demás productos de los vegetales, pertenecen al dueño de la tierra.

Así también las pieles, lana, astas, leche, cría y demás productos de los animales, pertenecen al dueño de estos" (Lo subrayado fuera del texto).

Señaló la Corte Suprema en sus consideraciones lo siguiente:

"Los frutos naturales pendientes pertenecen al propietario del bien raiz que los ha producido, pues esa es la regla general incorporada en el artículo 716 del Código Civil, toda vez que la excepción que dicha norma consagra en favor de los poseedores de buena fe se refiere especificamente a los frutos percibidos por tales detentadores antes de la notificación de la demanda" (Sentencia 16 de septiembre de 2011, Corte Suprema de Justicia).

En obediencia a lo dicho anteriormente por la Corte, como los pinos no habían sido percibidos al momento de la notificación de la demanda, debían ser restituidos por el predio, por lo tanto llega la Corte a la conclusión de que Pulpapel S.A. era responsable de los perjuicios causados a los herederos de Alfonso Pazos, por haberle 
causado un detrimento al predio. Puesto que según la Corte:

"En materia de frutos naturales, la regla general es que ellos pertenecen al dueño de la cosa que los produce, salvo las excepciones legales, o las que se deriven de lo decidido por los interesados, o lo establecido respecto del poseedor de buena fe, del usufructuario o del arrendatario (Art. 716, C.C.)" (Sentencia 16 de septiembre de 2011, Corte Suprema de Justicia). (Las subrayas son nuestras).

"A su turno, según las previsiones del articulo 964 del Código Civil, "[e]l poseedor de mala fe es obligado a restituir los frutos naturales y civiles de la cosa, y no solamente los percibidos sino los que el dueño hubiera podido percibir con mediana inteligencia y actividad teniendo la cosa en su poder", mientras que (...) “[e]l poseedor de buena fe no es obligado a la restitución de los frutos percibidos antes de la contestación de la demanda; en cuanto a los percibidos después, estará sujeto a las reglas de los dos incisos anteriores" (Las subrayas son nuestras).

Caso en el que se circunscribe Pulpapel S.A., ya que actuaba de buena fe, significando esto que solo estaba obligada a restituir los frutos percibidos después de la contestación de la demanda. Teniendo en cuenta esto, manifiesta la Corte:

"Establece una excepción a la regla general desarrollada en el artículo 716 ibídem, pues hace dueño al poseedor de buena fe de los frutos que haya percibido con anterioridad al enteramiento de la demanda, momento has- ta el cual puede atribuirsele dicha condición -la de poseedor de buena fe-, pues a partir de allí, en el supuesto de ser vencido en el proceso, se le dará el mismo tratamiento establecido para el poseedor de mala fe y, por lo mismo, estará obligado a la restitución de la totalidad de los frutos que perciba.

"De todo lo hasta aqui expresado se sigue que Pulpapel S.A., en acatamiento de la orden de restitución referida en el punto anterior, estaba obligada a entregar a los demandantes la finca "La Cohetera" con la plantación de pinos que estaba sembrada en ella, razón por la cual no podía, como lo hizo en 1995 y 1996, proceder a su tala y aprovechamiento, conducta que al reñir abiertamente con las disposiciones legales aquí señaladas, así como con la decisión de la que también ya se hizo mérito, deviene en un comportamiento ilícito, tanto más cuanto que con el mismo se afectó de manera ilegítima el círculo jurídico de actuación de los aquí demandantes, quienes no tienen el deber jurídico de soportar dicho detrimento" (Sentencia proferida por la Corte Suprema de Justicia el 16 de septiembre de 2011).

A pesar del razonamiento hecho por la Corte, en el que argumentativamente les da la razón a los herederos, al afirmar que por la naturaleza de los frutos, y por haber sido vencida en el proceso la empresa Pulpapel S.A. estaba obligada a la restitución de los frutos, la condena en la indemnización no prospera porque estos pidieron la indemnización por responsabilidad contractual y como el contrato ya no existía, dicha 
responsabilidad se había quedado sin fuente.

Vemos en este caso concreto, que la empresa Pulpapel de haber actuado conforme lo establece el artículo 1746, en cuanto a las restituciones, es decir, de haber devuelto el predio junto con las plantaciones, se habría visto gravemente afectada en el desarrollo de sus actividades económicas al no poderse concluir el contrato y más aún al tener que restituir la inversión hecha y perder la oportunidad de aprovechar su producto, ya que el artículo solo establece que sean reembolsados las mejoras necesarias, útiles y nada dice al respecto de los perjuicios como el lucro cesante por perder la oportunidad del aprovechamiento del producto de esas plantaciones.

En cuanto a la posición de los herederos, se observa que por no haber tramitado su indemnización sino con posterioridad a la declaratoria de nulidad, se quedaron sin una fuente específica para endilgarle la responsabilidad del daño causado por Pulpapel, ya que ellos enfocaron su acción en el plano contractual de manera errada, puesto que el contrato para el momento de su pretensión indemnizatoria ya no existía. Al respecto de este punto, puede pensarse en la sentencia judicial que declara la nulidad como fuente de la responsabilidad, ya que es esta la que ordena la restitución integral y es esta conducta la que Pulpapel no cumple.

\section{Soluciones normativas propuestas}

Una vez efectuado el análisis, vemos cómo en el plano de lo fáctico el planteamiento al que hago referencia con relación a los efectos de la nulidad consagrados en el artículo 1746 del
Código Civil puede ocasionar inequidades; por ello la propuesta que se plantea gira en torno a la modificación del actual artículo mencionado, de tal manera que se contemple dentro de este, la posibilidad abierta de que la parte afectada con la nulidad, habiendo actuado de buena fe, pueda ser resarcida -en los casos que lo amerite- en los perjuicios causados por la retrotracción del contrato, es decir, que se contemple la indemnización como una solución adicional más, en un contexto de reparación integral que permita poder llevar todo al estado anterior, para que desde la misma norma exista una cobertura total de perjuicios y no que precisamente no puedan reclamarse por deficiencias de la norma sustantiva o que estos perjuicios tengan que ser reclamados en procesos diferentes, por ello la propuesta que he estructurado para una mejor redacción del artículo es la siguiente:

"Artículo 1746. <efectos de la declaratoria de nulidad $>$ La nulidad pronunciada en sentencia que tiene la fuerza de cosa juzgada, da a las partes derecho para ser restituidas al mismo estado en que se hallarían si no hubiese existido el acto o contrato nulo; comprendiendo esto las restituciones e indemnizaciones a las que hubiere lugar por los perjuicios causados a la parte que actuó de buena fe y que se hubiere visto afectada por la nulidad, sin perjuicio de lo prevenido sobre el objeto o causa ilícita" (Lo subrayado sería la modificación que se propone).

"En las restituciones mutuas que hayan de hacerse los contratantes en virtud de este pronunciamiento, será cada cual responsa- 
ble de la pérdida de las especies o de su deterioro, de los intereses y frutos, y del abono de las mejoras necesarias, útiles o voluptuarias, tomándose en consideración los casos fortuitos, y la posesión de buena fe o mala fe de las partes; todo ello según las reglas generales y sin perjuicio de lo dispuesto en el siguiente artículo".

\section{CONCLUSIONES}

Hablar de la retrotracción del contrato como consecuencia de su declaratoria de nulidad, implica estudiar dos instituciones distintas, en primera medida la nulidad y luego la restitución, siguiendo la línea de Thibierge (2008), ya que desde el punto de vista de la funcionalidad de ambas figuras, estas son diferentes, puesto que la nulidad como sanción se limita a la supresión de los efectos jurídicos del negocio declarado nulo, es decir, solo a desaparecer el contrato como fuente jurídica de las actuaciones de las partes, mientras que la institución que se encarga de suprimir todas aquellas actuaciones realizadas en virtud del contrato es la restitución, por ello la distinción entre los efectos materiales y jurídicos que desencadena la celebración de un negocio determinado.

Los efectos jurídicos que se derivan de la celebración de un negocio jurídico son en esencia la creación, extinción o modificación de una situación jurídica determinada, o incluso su declaración o reconocimiento. En tanto que los efectos materiales consisten en el cumplimiento por una de las partes, de una prestación en eje- cución de su obligación prevista en el contrato, según Thibierge (2008).

En el artículo 1746 del Código Civil colombiano, al regular lo relacionado con los efectos de la declaratoria de nulidad, se observa una mixtura entre la nulidad y la restitución, en tanto que la nulidad es concebida como una acción mixta, al señalar como efecto de la nulidad la restitución, incluyendo en este mismo artículo dos figuras jurídicas diferentes, según se ha explicado precedentemente.

Una vez estudiadas las falencias de la redacción actual del artículo 1746 del Código Civil, que regula los efectos de una de las sanciones más importantes a los negocios jurídicos y de observar en el plano material la trascendencia de estas fallas en la norma, la conclusión más inmediata a la que se puede arribar es la necesidad de modificar el texto normativo.

Al proponer una nueva redacción lo que se pretende es iniciar el debate para la construcción de una mejor herramienta normativa que sirva a los contratantes actuales para evitar los conflictos de esta índole, y para garantizar un proceso menos a la ya tan congestionada justicia colombiana.

Otra conclusión a la se puede llegar con este estudio, consiste en cambiar el paradigma y darnos cuenta de que no solo son las normas procesales o de Derecho adjetivo y sus modificaciones, las que van a agilizar los procesos y a descongestionar la justicia, sino que también desde la reestructuración de ciertas figuras conflictivas en el Derecho sustantivo, se puede evitar el origen de conflictos posteriores. 


\section{REFERENCIAS}

Baraona, J. (2006). Nulidad de contratos e indemnizaciones. Revista del abogado $N^{\circ} 38$, pp. 26-29, Chile.

Congreso de la República de Colombia. Ley 57 de 1887, Código Civil Colombiano.

Corte Suprema de Justicia de Colombia. Sentencia 16 de septiembre de 2011, Magistrado Ponente Arturo Solarte Rodríguez, rad. 19001-3103-003-2005-00058-01.

Corte Suprema de Justicia. Sentencia 22 de abril de 1994, Juzgado Primero Civil del Circuito de Cali, proceso de nulidad contractual promovido por Alfonso, Natalia, Marcia Alejandra, Alicia y Guillermo Pazos Álvarez, Luz Mar Pazos López y Manuel Andrés Pazos Cadena contra Celulosa y Papel de Colombia S.A. -Pulpapel.
Ghersi, C. (2005). Nulidades de los actos jurídicos. Buenos Aires: Editorial Universidad.

Namen, W. (2010). A propósito de reforma a la administración de justicia. Revista 29, Corte Suprema. Corte Suprema de Justicia.

Poveda, A. (2010). Reformas al Estado: la hora de tomar en serio la administración de justicia. Revista 29, Corte Suprema. Corte Suprema de Justicia.

Thibierge, C. (2008). Segunda parte. Ensayo de una nueva teoría sobre la nulidad. Nulidad, restituciones y responsabilidad. (pp. 361371). Bogotá: Universidad Externado de Colombia.

Zannoni, E. (2004). Ineficacia y nulidad de los Actos Jurídicos. Buenos Aires: Editorial Astrea. 